\title{
Comparison of Two Methods of Epidural Steroid Injection in the Treatment of Recurrent Lumbar Disc Herniation
}

\author{
Saeid Karamouzian ${ }^{1,2}$, Ali Ebrahimi-Nejad ${ }^{1}$, Shahram Shahsavarani ${ }^{1}$, \\ Ehsan Keikhosravi ${ }^{3}$, Mohsen Shahba ${ }^{1}$, Farzaneh Ebrahimi ${ }^{1}$ \\ ${ }^{1}$ Neuroscience Research Center, Institute of Neuropharmacology, Kerman University of Medical Sciences, Kerman, Iran \\ ${ }^{2}$ Afzal Research Institute (NGO), Kerman, Iran \\ ${ }^{3}$ Neurosurgery Department, Mashhad University of Medical Sciences, Mashhad, Iran
}

\begin{abstract}
Study Design: Prospective study.
Purpose: We compared the effects of two methods of epidural steroid injection in patients with recurrent disc herniation.

Overview of Literature: To our knowledge, there is no previous report of such a comparison in these patients.

Methods: The study was performed with 30 patients with relapsed lumbar disc herniation whose pain was not relieved by conservative remedies. The patients were divided into two groups, each of 15 patients, and entered the study for caudal or transforaminal injections. The degree of pain, ability to stand and walk, and the Prolo function score were evaluated in both groups before the injection and 2 months and 6 months after the injection.

Results: The degrees of pain reduction in the caudal injection group in the second and sixth months were 0.6 and 1.63, respectively, and in the transforaminal injection group were 1.33 and 1.56, respectively. The difference between the two methods was not statistically significant. Similarly, no other evaluated criterion showed a significant difference between the methods.

Conclusions: In the current study, the caudal and transforaminal steroid injection methods showed similar outcomes in the treatment of relapsed lumbar disc herniation. However, more detailed patient categorizing may help in finding possible subgroups with differences.
\end{abstract}

Keywords: Lumbar spine; Recurrent disc herniation; Epidural steroid; Caudal; Transforaminal

\section{Introduction}

Lumbar and leg pain are among the most common causes of disability in Western societies. Such disabilities may have several causes but lumbar disc herniation alone accounts for about $50 \%$ of cases [1].

Epidural steroid injection (ESI) is the most commonly used intervention in treatment of the pain of disc hernia- tion [2-4]. Epidural steroid injections are performed in three ways: caudal, interlaminar, and transforaminal (TF). The TF method is favored because less drug is needed for the injection and because of the proximity of the injection site to the nerve root [5]. Furthermore, diffusion of the drug to the anterior part of the sac is more feasible $[6,7]$. The analgesic properties of the interlaminar method have been demonstrated in many studies [8]. Although some

Received Oct 5, 2013; Revised Feb 11, 2014; Accepted Feb 19, 2014

Corresponding author: Saeid Karamouzian

Neuroscience Research Center, Institute of Neuropharmacology, Kerman University of Medical Sciences, Kerman, Iran

Tel: +98-91-3341-5316, Fax: +98-34-1247-7925, E-mail: Karamouzian@gmail.com

*The study was supported by Neuroscience Research Center, Kerman University of Medical Sciences. 
side effects, such as paraplegia, increased blood pressure [8], and even death (Smuck), have been reported, the procedure is considered safe because these complications are very rare $[8,9]$. The caudal method has been demonstrated to have acceptable analgesic effects and is easier to perform than the other two methods [5].

After discectomy, however, symptoms may relapse in $5 \%$ to $40 \%$ of cases [10], and in cases of prolonged follow-up, the relapse rate will be even higher [10]. The main reasons are relapsed disc herniation and nerve root compression, epidural fibrosis, foraminal or lateral canal stenosis, segmental instability, facet joints, and myofascial pain syndromes [11-13]. The presence of adhesions will increase the probability of nerve root damage and rupture of the dura mater in a second operation [10]. Because a second operation has less favorable outcomes, alternative treatment methods may be more attractive [14].

Some researchers have studied the effects of epidural steroid injections in patients with relapsed disc herniation $[15,16]$, but to our knowledge, there is no report comparing the effectiveness of the different methods of ESI in these patients. Adhesion at the site of a laminectomy increases the rate of dural puncture during an interlaminar epidural injection, so we sought to compare the transforaminal and caudal methods in this study.

\section{Materials and Methods}

The Medical Ethics Committee of the Kerman Neuroscience Research Center approved the study protocol. Those who entered the study received information about the side effects and probable complications. Written informed consent was obtained from each participant. The trial is registered in the Iranian Registry of Clinical Trials (IRCT138903084047N1).

Sampling was done during a 17 -month period, from June 12, 2009 to November 22, 2010. The inclusion criteria were as follows: 1) a previous episode of successful lumbar open discectomy due to lumbar disc herniation, 2) recurrent radicular pain that was not responsive to at least 6 weeks of continuous treatment, 3) age of 18 or older, and 4) recurrent disc herniation at the same level, ipsilateral to the side of the previous operation, as verified by lumbar spine magnetic resonance imaging (MRI) (Fig. 1) [17-19].

We excluded patients with severe central disc herniation, based on MRI findings, significant or progressive neurologic deficits, patients who had undergone previous epidural steroid injections, patients with coagulation disorders or known allergies to analgesics or corticosteroids, and pregnant women.

The patients were randomly assigned to the caudal and transforaminal groups in a 1:1 ratio, using block randomization. All procedures were performed in Bahonar Hospital, which is supervised by Kerman University of Medical Sciences. Before they entered the operating room, $0.5-2 \mathrm{mg}$ of midazolam had been injected intravenously. The patients were placed in a prone position and, after disinfection with betadine, the skin was anesthetized with $1 \%$ lidocaine.

In the transforaminal method, a 20-gauge LP needle was placed anterosuperiorly towards the foramen under fluoroscopy guidance (Fig. 2), and after confirmation of the correct positioning of the needle, $40 \mathrm{mg}$ of depomedrol, $1 \mathrm{~mL}$ of bupivacaine, and $1 \mathrm{~mL}$ of $2 \%$ lidocaine were injected.

In the caudal method $40 \mathrm{mg}$ of depomedrol, $1 \mathrm{~mL}$ of $2 \%$ lidocaine, and $1 \mathrm{~mL}$ bupivacaine $0.25 \%$ and $7 \mathrm{~mL}$ of distilled water (total, $10 \mathrm{~mL}$ ) were injected via a 22 -gauge needle from the sacral notch. After the injection, patients were observed the in hospital for 30-60 minutes and then discharged.

All patients underwent treatment with tizanidine 6-12 mg per day for 7 days to relieve muscle spasm, celecoxib

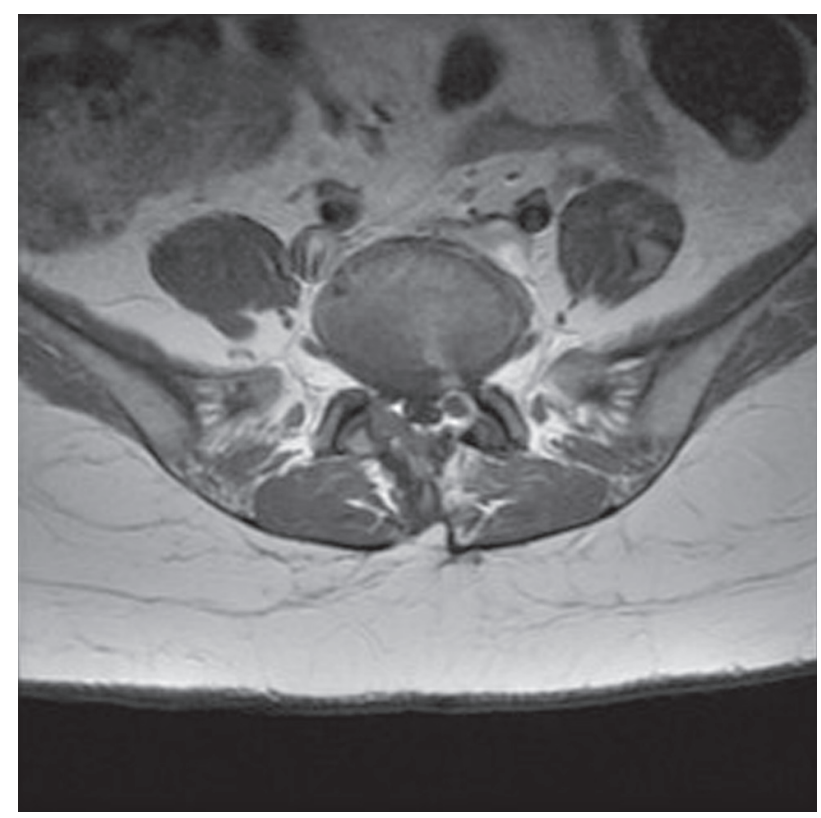

Fig. 1. Lumbar spine magnetic resonance imaging with gadolinium shows recurrent disc herniation at the same level. 
Table 1. Summarizes demographic data of both groups

\begin{tabular}{lccc} 
& Transforaminal & Caudal & $p$-value \\
Age (mean \pm standard deviation) & $47.33 \pm 9.48$ & $48.33 \pm 11.74$ & 0.84 \\
Female gender (\%) & 53.3 & 53.3 & 1.00 \\
L4-L5 level (\%) & 80 & 66.7 & 0.682 \\
\hline
\end{tabular}

100-200 mg per day for 7 days to relieve pain, and nortriptyline 25-100 mg per day for 21 days. The severity of the pain sensed by the patients had been asked and registered according to the NPS table before the procedures.

The patients were then followed via phone at 2,4 , and 8 weeks and 6 months later [20]. After asking patients about their ability to do their daily affairs, using the Prolo scales table [21], their function was recorded. A walking tolerance test was performed according to the ability of the patients to walk without feeling pain, and patient responses were recorded using the 'foot' scale. A standing tolerance test was performed according to the ability of the patients to stand without feeling pain, and patient responses were recorded using the 'minute' scale. The number of rest days was recorded according to the days in which patients could not do their routine daily affairs because of back pain, and patient responses were recorded using the 'day' scale.

After descriptive statistical analyses were performed using the SPSS software (ver. 10.0), comparisons between the two groups were made using Student's $t$-test for parametric and the Mann-Whitney $U$-test for non-parametric data. The $\chi^{2}$ statistic was used to test differences in pro-

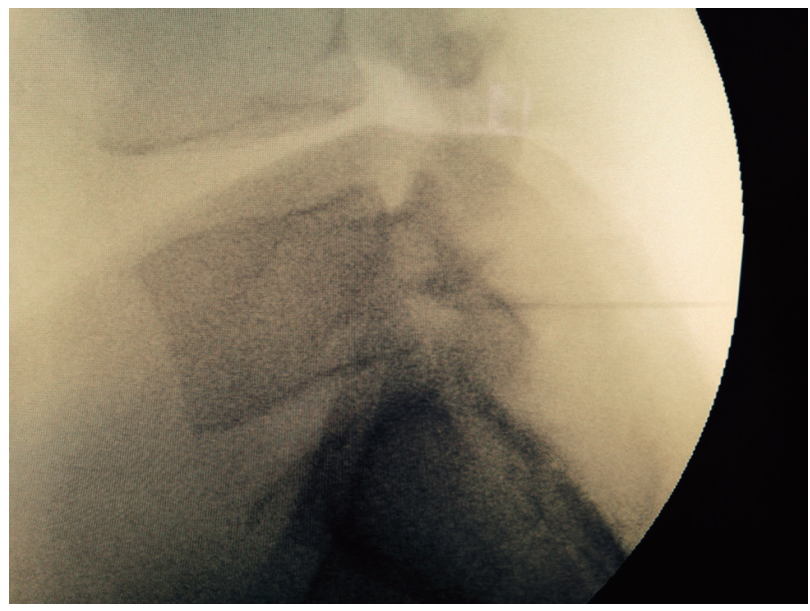

Fig. 2. The location of the needle in the foramina.
Table 2. Severity of pain and other evaluated criteria in both groups before the injection

\begin{tabular}{lcc} 
& Caudal & Transforaminal \\
\hline Pain intensity & $6.13 \pm 1.64$ & $6.33 \pm 1.35$ \\
\hline Standing tolerance & $18.27 \pm 22.57$ & $9.13 \pm 9.05$ \\
Walking tolerance & $166.80 \pm 342.20$ & $133.40 \pm 273.33$ \\
Rest days & $8.27 \pm 5.61$ & $6.67 \pm 3.85$ \\
\hline
\end{tabular}

Values are presented as mean \pm standard deviation.

portions and a paired $t$-test was used to compare the preand post-treatment results of average pain. Results were considered statistically significant if the $p$-value was less than 0.05

\section{Results}

In the 17 -month period, 32 patients entered the study. Two cases needed early operations because of neurological deficits. In total, 30 patients met our criteria with an average age of $48 \pm 10.51$ years, $14(46.6 \%)$ male and 16 (53.4\%) female cases, who had undergone discectomies $18 \pm 6$ months earlier. In $22(73.3 \%)$ cases, prior surgeries had been performed at the level of the disc between L4 and L5, and in 6 (20\%) cases, at the level of L5-S1. A foraminotomy had been performed in all 30 patients. These patients' pain scores had been established $14.4 \pm 6.5$ weeks earlier. The severity of pain, according to the NPS scale, was $6.23 \pm 1.48$, the standing ability score was $17.52 \pm 13.70$, and the walking ability score was $304 \pm 149.10$ feet.

There was no significant difference in age, gender, level of involvement, or time passed since surgery between two groups. Patient details are provided in Table 1. Table 2 compares the severity of pain and other criteria evaluated in the patients.

Patients in the caudal group underwent ESIs via the caudal method and the transforaminal group via the transforaminal method. At 2 months after the injections, 
Table 3. Pain intensity 6 months after the injection

\begin{tabular}{lccc} 
& Caudal & Transforaminal & $p$-value \\
Pain intensity & $4.5 \pm 1.0$ & $4.77 \pm 0.93$ & 0.827 \\
Standing tolerance & $26.67 \pm 24.71$ & $17.69 \pm 10.13$ & 0.612 \\
\hline
\end{tabular}

Values are presented as mean \pm standard deviation.

Table 4. Pre- to post-treatment comparisons of the Prolo index between two groups

\begin{tabular}{lccc} 
& Before treatment & Two months after treatment & \multicolumn{2}{c}{ Six months after treatment } \\
Economic status & C 2 & C 2 & C 3 \\
Functional status & TF2 & TF 2 & TF2 \\
& C 1 & C 2 & C 3 \\
\hline
\end{tabular}

C, caudal; TF, transforaminal.

the pain score in the first group reached $5.53 \pm 1.51$, from $6.13 \pm 1.64$, and in the second group reached $5.0 \pm 0.93$, from $6.33 \pm 1.35$. Thus, the mean pain reduction with the caudal method was 0.6 and 1.33 with the transforaminal method; this difference was not statistically significant $(p=0.184)$.

Over the same time period, the patients' tolerance to walking in the first group reached 249.26 \pm 129.0 , from $342.20 \pm 166.8$, and in the second group reached $267.4 \pm 169.23$, from $273.33 \pm 131.40$. Thus, during this period, walking tolerance decreased by 37.80 units in the caudal group and increased by 57.87 units in the transforaminal group; however, this difference was also not statistically significant $(p=0.30)$.

The patients' tolerance for standing in group caudal reached $20.17 \pm 17.53$, from $22.57 \pm 18.27$, and in group transforaminal reached $14.67 \pm 11.57$, from $9.13 \pm 9.05$. Thus, during this period, standing tolerance decreased by 0.80 units in the caudal group and increased by 5.54 units in transforaminal group; this difference was not statistically significant $(p=0.10)$.

The mean rest days in the caudal group increased by 1.6 days and decreased by 1.11 days in the transforaminal group; this difference was also not significant $(p=0.37)$. All criteria were then re-evaluated at the end of a 6-month period; these results are presented in Table 3 .

A comparison between the groups according to the Prolo scoring system before treatment and at the end of the second and sixth months is shown in Table 4 .
One patient suffered temporary paraparesis in group caudal. We did not see any other complication.

\section{Discussion}

Although inflammatory disorders are among the important causes of low back pain, inflammation has been shown to be present even with mechanical etiologies of low back pain. Many animal studies have revealed that some cytokines, such as tumor necrosis factor alpha, which are synthesized by macrophages in the nucleus pulposus, on reaching the nerve root, can start pathophysiological changes that induce pain sensations and sensory deficits $[5,22,23]$. The role of inflammatory and chemical mediators in pain induction explains the success of steroid use in the treatment of low back pain and radicular pain caused by lumbar disc herniation [24,25].

Many studies have investigated the effects of the epidural steroid injections, but few have compared different methods of the injection in primary lumbar disc herniation. The superiority of the transforaminal method has been supported by some RCTs [8]. However, this remains controversial. Mendoza-Lattes et al. [26] compared the caudal method to the transforaminal method in patients with primary lumbar disc herniation. The transforaminal method showed better results, but the difference was not statistically significant. Despite the controversy, it is commonly accepted that the transforaminal injection has better results because of better distribution of the drug to 
the anterior part of the sac $[6,7]$.

In our study, the transforaminal epidural injection did have better results than to the caudal injection method; however, none of the differences were statistically significant. Although different studies have reported up to $84 \%$ efficacy for the transforaminal injection method in the treatment of the primary lumbar disc herniation [27], our response rate with the transforaminal method was only $40 \%$, considerably lower than some of those studies. Buenaventura et al. [8] also reported a low response rate after transforaminal steroid injection in patients with recurrent disc herniation, which may have been due to epidural fibrosis. A peridural scar is capable of binding the dura and nerve roots to the circumferentially surrounding structures and in animal models of post-lumbar laminectomy nerve root adherence to the underlying disc and pedicle has been demonstrated [28]. The pattern of epidural fibrosis in humans is not well known; however, it is supposed that fibrosis would appear at the junction of the dura mater with a hematoma [28]. In our study, all the patients underwent a foraminatomy in their previous operation. It is possible that adhesion in the foramina, which was already compromised by the herniated disc, restricted the distribution of the drug to the anterior part of the sac through the foramina. However, it is known that innervation to the annulus and its peripheral ligaments is multi-segmental, and in some studies it has even been stated that pain transferring via sympathetic routes will not be relieved by nerve block below the level of L2 [29]. This mechanism may make the transforaminal method more vulnerable to fibrosis and adhesion.

We did not use a contrast material during the transforaminal epidural injection to evaluate the distribution of the steroid. Attempts to quantify the amount and location of peridural fibrosis after lumbar discectomy may help in choosing the most appropriate method for the epidural injection.

Manchikanti et al. [30] showed that the caudal injection decreased chronic low back pain significantly and radicular pain in $65 \%$ of the patients with recurrent disc herniation, which was higher than our result. In that study, cases with facet joint involvement were excluded. It has been reported that pain originates from the facet joints in $17 \%$ to $24 \%$ of the patients with FBSS, and it is recommended to perform a facet block test to diagnose facet joint involvement [13]. However, this test is not very sensitive or specific. We did not perform the test, and probably some of our cases had facet joint involvement; this may explain our lower response rate. We also did not use fluoroscopy during caudal injections. Manchikanti et al. [30] reported that injection without fluoroscopy guidance was associated with an inappropriate site of the injection in 30\% of cases, which can decrease the distribution of the drug to the site of the inflammation and nerve compression. This may also explain our lower response rate. Revel et al. [16] showed that a forceful caudal injection had a $49 \%$ response rate versus $19 \%$ in a routine injection; the difference was statistically significant. The results for the caudal method in our study resemble the results of the caudal injection without force in Revel et al.s study. It is possible that if we had used a forceful injection, our results would have been better, but further investigations are required to assess this.

One limitation of our study is the absence of a control group. The presence of a control group could help in interpreting the results. However, our major goal was to compare the two methods of the epidural injection, not the effect of the epidural injection on relapsed disc herniation. Second, the presence of a control group could impair our randomization. It should not be forgotten that not all the causes of recurrent pain are related to disc herniation or epidural fibrosis and other etiologies, such as degeneration of the adjacent disc, facet joint involvement, and fibrosis of the nerve root can also be causes of relapse pain [11]. Among these etiologies, relapsed discs and canal stenosis respond partially to epidural injections $[13,15]$. Epidural fibrosis, which occurs in $20 \%$ to $36 \%$ of "failed back syndrome," may respond to epidural injection, but the response is very short-term $[13,15]$. Using a single treatment remedy for a heterogeneous group of diseases with similar symptoms may explain treatment failure.

Although epidural steroids have a short-term effect, their use along with other modalities of treatment may help relieve pain and enhance patient function. It would seem that the relatively low response rate could be improved by better categorizing patients and enhancing the injection methods. However, generally increased knowledge about the pattern of epidural adhesion may also help in choosing the most appropriate injection method.

\section{Conclusions}

Epidural steroid injection via the caudal and transforami- 
nal methods in patients with relapsed disc herniation showed similar effects in terms of pain and patient function. Better categorizing of patients may help in achieving better outcomes.

\section{Conflict of Interest}

No potential conflict of interest relevant to this article was reported.

\section{Acknowledgments}

We are grateful to Ehsan Mehrabi Kermani for editing the English text.

\section{References}

1. Manchikanti L, Singh V, Falco FJ, Cash KA, Pampati $\mathrm{V}$. Evaluation of the effectiveness of lumbar interlaminar epidural injections in managing chronic pain of lumbar disc herniation or radiculitis: a randomized, double-blind, controlled trial. Pain Physician 2010;13:343-55.

2. Friedly J, Nishio I, Bishop MJ, Maynard C. The relationship between repeated epidural steroid injections and subsequent opioid use and lumbar surgery. Arch Phys Med Rehabil 2008;89:1011-5.

3. Krych AJ, Richman D, Drakos M, et al. Epidural steroid injection for lumbar disc herniation in NFL athletes. Med Sci Sports Exerc 2012;44:193-8.

4. Abdi S, Datta S, Trescot AM, et al. Epidural steroids in the management of chronic spinal pain: a systematic review. Pain Physician 2007;10:185-212.

5. Atcheson SG, Dymeck T. Rapid resolution of chronic sciatica with intravenous infliximab after failed epidural steroid injections. Spine (Phila Pa 1976) 2004;29:E248-50.

6. Jeong HS, Lee JW, Kim SH, Myung JS, Kim JH, Kang HS. Effectiveness of transforaminal epidural steroid injection by using a preganglionic approach: a prospective randomized controlled study. Radiology 2007;245:584-90.

7. Roberts ST, Willick SE, Rho ME, Rittenberg JD. Efficacy of lumbosacral transforaminal epidural steroid injections: a systematic review. PM R 2009;1:657-68.

8. Buenaventura RM, Datta S, Abdi S, Smith HS. Systematic review of therapeutic lumbar transforaminal epidural steroid injections. Pain Physician 2009;12: 233-51.

9. McGrath JM, Schaefer MP, Malkamaki DM. Incidence and characteristics of complications from epidural steroid injections. Pain Med 2011;12:726-31.

10. Chen Z, Zhao J, Liu A, Yuan J, Li Z. Surgical treatment of recurrent lumbar disc herniation by transforaminal lumbar interbody fusion. Int Orthop 2009; 33:197-201.

11. Bokov A, Isrelov A, Skorodumov A, Aleynik A, Simonov A, Mlyavykh S. An analysis of reasons for failed back surgery syndrome and partial results after different types of surgical lumbar nerve root decompression. Pain Physician 2011;14:545-57.

12. Epter RS, Helm S 2nd, Hayek SM, Benyamin RM, Smith HS, Abdi S. Systematic review of percutaneous adhesiolysis and management of chronic low back pain in post lumbar surgery syndrome. Pain Physician 2009;12:361-78.

13. Manchikanti L, Singh V, Falco FJ, Cash KA, Pampati V. Lumbar facet joint nerve blocks in managing chronic facet joint pain: one-year follow-up of a randomized, double-blind controlled trial: Clinical Trial NCT00355914. Pain Physician 2008;11:121-32.

14. Shin KH, Chang HG, Rhee NK, Lim KS. Revisional percutaneous full endoscopic disc surgery for recurrent herniation of previous open lumbar discectomy. Asian Spine J 2011;5:1-9.

15. Manchikanti L, Singh V, Cash KA, Pampati V, Datta S. Preliminary results of a randomized, equivalence trial of fluoroscopic caudal epidural injections in managing chronic low back pain: Part 3--Post surgery syndrome. Pain Physician 2008;11:817-31.

16. Revel M, Auleley GR, Alaoui S, et al. Forceful epidural injections for the treatment of lumbosciatic pain with post-operative lumbar spinal fibrosis. Rev Rhum Engl Ed 1996;63:270-7.

17. Anderson SR. A rationale for the treatment algorithm of failed back surgery syndrome. Curr Rev Pain 2000;4:395-406.

18. Arts MP, Peul WC, Koes BW, Thomeer RT; LeidenThe Hague Spine Intervention Prognostic Study (SIPS) Group. Management of sciatica due to lumbar disc herniation in the Netherlands: a survey among spine surgeons. J Neurosurg Spine 2008;9:32-9.

19. Buttermann GR. Treatment of lumbar disc herniation: epidural steroid injection compared with dis- 
cectomy. A prospective, randomized study. J Bone Joint Surg Am 2004;86:670-9.

20. Rosenberg SK, Grabinsky A, Kooser C, Boswell MV. Effectiveness of transforaminal epidural steroid injections in low back pain: a one year experience. Pain Physician 2002;5:266-70.

21. Porchet F, Wietlisbach V, Burnand B, Daeppen K, Villemure JG, Vader JP. Relationship between severity of lumbar disc disease and disability scores in sciatica patients. Neurosurgery 2002;50:1253-9.

22. Borenstein DG. Epidemiology, etiology, diagnostic evaluation, and treatment of low back pain. Curr Opin Rheumatol 2001;13:128-34.

23. Owlia MB, Salimzadeh A, Alishiri G, Haghighi A. Comparison of two doses of corticosteroid in epidural steroid injection for lumbar radicular pain. Singapore Med J 2007;48:241-5.

24. Khan MU, Hussain SZ. Role of psoas compartment and caudal epidural steroid injection in spinal stenosis patients associated with low back pain and lower limb radiculopathy. J Pak Med Assoc 2008;58:490-3.

25. Rinehart JJ, Sagone AL, Balcerzak SP, Ackerman GA,
LoBuglio AF. Effects of corticosteroid therapy on human monocyte function. N Engl J Med 1975;292:23641.

26. Mendoza-Lattes S, Weiss A, Found E, Zimmerman B, Gao Y. Comparable effectiveness of caudal vs. transforaminal epidural steroid injections. Iowa Orthop J 2009;29:91-6.

27. Lee JH, An JH, Lee SH. Comparison of the effectiveness of interlaminar and bilateral transforaminal epidural steroid injections in treatment of patients with lumbosacral disc herniation and spinal stenosis. Clin J Pain 2009;25:206-10.

28. Lee JG, Lee SC, Kim YC, et al. Effects of low and high molecular weight hyaluronic acids on peridural fibrosis and inflammation in lumbar laminectomized rats. Korean J Pain 2011;24:191-8.

29. Sluijter ME. The role of radiofrequency in failed back surgery patients. Curr Rev Pain 2000;4:49-53.

30. Manchikanti L, Cash KA, Pampati V, McManus CD, Damron KS. Evaluation of fluoroscopically guided caudal epidural injections. Pain Physician 2004;7:8192. 